Artículos

\title{
A periferia na periferia: sobre o lugar da antropologia da educação na antropologia latino-americana*
}

La periferia de la periferia: sobre el lugar de la antropología de la educación en la antropología latinoamericana The Periphery in the Periphery: About the Place of the Anthropology of Education in Latin American Anthropology

Amurabi Oliveiraa

Universidade Federal de Santa Catarina, Brasil amurabi_cs@hotmail.com

ORCID: https://orcid.org/0000-0002-7856-1196

DOI: https://doi.org/10.11144/Javeriana.uh89.ppla

Recepção: 17 Setembro 2019

Aprovação: 29 Maio 2020

Publicação: 30 Junho 2020

\section{Resumo:}

O campo da antropologia tem sido marcado por uma constante autorreflexão sobre sua própria realidade, desenvolvimento histórico e perspectivas de futuro, de modo que em período mais recente tem havido uma crescente problematização em torno das estruturas de poder constituídas nesse campo, e sobre as hierarquias desdobradas de tais estruturas, que produzem "antropologias hegemônicas" e "antropologias periféricas". Entretanto, pouco ainda tem sido discutido sobre as hierarquias dentro das próprias "antropologias periféricas", neste sentido, este artigo visa contribuído para esse debate, situando a antropologia da educação na agenda de pesquisas das antropologias latino-americanas. Levanta-se como hipótese que a antropologia da educação na América Latina é duplamente periférica, pois é produzida desde essa região geopolítica, e é também invisibilizada enquanto campo de investigação antropológica.

Palavras-chave: antropologia latino-americana, antropologia da educação, antropologias do sul, antropologias mundiais.

\section{Resumen:}

El campo de la antropología ha sido marcado por una constante autorreflexión sobre su propia realidad, desarrollando histórico y perspectivas de futuro, de tal modo que en los periodos más recientes ha habido una creciente problematización en torno de las estructuras de poder constituidas en ese campo, y sobre las jerarquías desdobradas de tales estructuras, que producen "antropologías hegemónicas" y "antropologías periféricas". Mientras tanto, todavia no se discute suficiente sobre las jerarquías dentro de las propias “antropologías periféricas". En este sentido, este artículo busca contribuir en ese debate, situando la antropologia de la educación en la agenda de investigación de las antropologías latinoamericanas. Se plantea como hipótesis que la antropología de la educación en América Latina es doblemente periférica, pues es producida desde esa región geopolítica y así como es invisibilizada en tanto campo de investigación antropológica.

Palabras clave: antropología latinoamericana, antropología de la educación, antropologías del sur, antropologías mundiales.

\section{Abstract:}

The field of anthropology has been marked by a constant self-reflection about its own reality, historical development and future prospects, so that in a more recent period there has been a growing problematization around the power structures constituted in this field, and about the hierarchies of such structures that produce "hegemonic anthropologies" and "peripheral anthropologies." However, few has been discussed about the hierarchies within the "peripheral anthropologies", in this sense, this article aims to contribute to this debate, placing the anthropology of education in the research agenda of Latin American anthropologies. It is hypothesized that the anthropology of education in Latin America is doubly peripheral, since it is produced from this geopolitical region, and is also invisible as a field of anthropological research.

Keywords: Latin American anthropology, anthropology of education, anthropologies of the south, world anthropologies.

\section{Introdução}

Certamente em países nos quais as desigualdades sociais são bastante profundas a educação passa a ser depositária de esperanças e aspirações, acionada recorrentemente nas políticas públicas e sendo compreendida 
como chave para a superação de parte significativa dos problemas sociais. Todavia, apesar da relevância social da educação, especialmente nos países da América Latina, historicamente esse tem sido um problema que pouco tem ocupado a agenda de pesquisa dos antropólogos. No caso brasileiro, que é o meu lugar de fala, recorrentemente os pesquisadores chegam à educação enquanto objeto de estudo movidos pelo acasos do trabalho de campo, como destacou a antropóloga Neusa Gusmão em entrevista recente (Oliveira, 2013a).

Entretanto, apesar dos pontos em comum que existem nessa região geopolítica e cultural que é a América Latina, há de se considerar as particularidades que envolvem o desenvolvimento das discussões existentes nas diversas tradições intelectuais dos distintos países. Resumir a educação a um tema pouco explorado pela antropologia latino-americana acaba por visibilizar muito pouco a complexidade aí existente, que espelha, obviamente, a própria diversidade cultural que há nessa região.

Partindo de minha própria inserção no campo da antropologia da educação no Brasil, mas também considerando os intercâmbios acadêmicos que venho realizando com pesquisadores de países como Argentina, Colômbia, Chile e México, buscarei realizar um breve balanço da antropologia da educação na América Latina, problematizando seu desenvolvimento institucional. Logo em seguida, buscarei situar a antropologia da educação na América Latina, pensando essa realidade desde uma geopolítica do conhecimento, para que com isso possamos vislumbrar os desafios que se colocam na inserção desta temática na agenda de pesquisa mais ampla das antropologias latino-americanas.

Acentua-se que nesse trabalho, apesar de considerarmos os diversos aspectos que envolvem a antropologia da educação, desde o debate sobre educação superior, educação não-escolar, educação cultural indígena etc., preocupo-me, sobretudo, com o debate sobre uma antropologia dos sistemas de educação básica. Incorrendo no risco de assumir a parte pelo todo, esse recorte assume como pressuposto a centralidade que tais sistemas ocupam nas sociedades latino-americanas atualmente, e de como constituem um processo central nas transformações socioculturais e políticas destas sociedades.

O exercício teórico aqui empreitado parte de um diálogo com a literatura produzida sobre antropologia da educação na interface com aquela acerca da antropologia latino-americana, antropologias do sul, antropologias mundiais e Estudos Pós-Coloniais. Trata-se, em última instância, de situar a antropologia da educação nas antropologias latino-americanas, anunciando seus desafios.

\section{Por uma antropologia da educação na América Latina}

Pensar o percurso antropologia da educação na América Latina só faz sentido quando inserido na história mais ampla da própria disciplina Antropológica. Mais que isso, devemos compreender as antropologias latinoamericanas dentro da complexa teia de relações de poder que há na geopolítica acadêmica. Compreendo assim, que estas antropologias estão sempre em relação ao que Lins Ribeiro e Escobar (2012, pp. 23-24) denominam de antropologias Hegemônicas, que seriam “[...] um conjunto de formações discursivas e práticas institucionais associadas à normalização da antropologia acadêmica, principalmente nos Estados Unidos, no Reino Unido e na França”.

Também é importante destacar, como bem realiza Medina (1993), que as antropologias desenvolvidas no sul global são realizadas sob condições distintas daquelas que se encontram no norte global, de tal modo que se mostra contraproducente avaliar a antropologia elaborada na América Latina a partir de uma perspectiva forjada no norte global.

Todavia, seria ingênuo acreditar que as antropologias latino-americanas se colocam apenas como um continuum com relação às antropologias hegemônicas, pois mesmo diante da assimilação de teorias, conceitos e instrumentos investigativos, há o desenvolvimento aqui de marcas próprias nessas antropologias. Como nos indica Jimeno (2005, p. 53): 
La antropología, tanto como la creacion literaria y artistica, muy cercanas entre sí, han sido en América Latina naciocéntricas en su producción conceptual. Pero, a diferencia de lo que Elias señalaba para Europa, nuestra condición histórica como naciones en construcción a partir de una común experiencia y ruptura coloniales hace que nuestra producción cultural esté atravesada por propuestas polémicas sobre el Estado y la Nación que se quieren construir. Por ello tenemos una larga historia de teoría crítica que se expresa en la diversidad de lenguajes individuales y generacionales, y cuyos conceptos pretenden capturar no la lejanía, sino la proximidad sociopolítica del Otro.

Portanto, estamos nos referindo a antropologias tendencialmente engajadas, implicadas nos processos de construção da nação. Os fundamentos epistemológicos das antropologias latino-americanas estão, portanto, assentados numa compreensão de cultura que leva esses elementos em consideração. Os conceitos de culturas aqui operados só fazem sentido ante a compreensão da centralidade dos processos coloniais aqui ocorridos, nos quais a questão racial é uma das mais centrais (Quijano, 2010). Tal questão indica por si só um hiato entre as antropologias desenvolvidas na América Latina e as antropologias hegemônicas, especialmente se considerarmos que as teorias sociais eurocêntricas prescindem de uma reflexão que envolva tal experiência (Connell, 2006).

Ainda nessa direção é emblemática a centralidade e impacto da obra de Paulo Freire (1921-1997) no debate educacional latino-americano, distando das teorias da reprodução que centraram suas análises do papel que os sistemas de ensino desempenhariam na reprodução das desigualdades sociais, o trabalho de Freire apontava para o caráter emancipatório que a educação poderia assumir. Desse modo, tais ideias estavam profundamente afinadas com o que encontramos no debate presente nas ciências sociais latino-americanas, e na antropologia em particular.

Se para Stocking Jr. (1982) a tradição da antropologia euro-americana pode ser distinguida entre "antropologias de construção do império" e "antropologias de construção da nação", penso que encontramos na América Latina são antropologias da construção da nação em contínua relação com as antropologias de construção do império. A depender os vínculos históricos e intelectuais de cada país, encontraremos uma relação mais ou menos incisiva com determinadas tradições intelectuais, sobretudo anglófonas e francófonas.

Parece-me que o desenvolvimento de nossas antropologias subverte a questão central das antropologias nas tradições euro-americanas, pois o ponto não é “quem são eles?", mas sim, “quem somos nós?". Isso em parte poderia explicar a centralidade de categorias tais como raça, mestiçagem e interculturalidade nesse cenário, poise se mostram centrais no processo de autocompreensão dos povos latino-americanos.

As antropologias Latino-Americanas ao se indagarem quem nós somos também desemborcam em questões de cunho mais pragmático, que se relacionam ao aventamento da viabilidade das nações em América Latina. As etnografias históricas como Contrapunteo cubano del tabaco y del azúcar de Fernando Ortiz, publicada em 1940 em Cuba, e Casa-Grande \& Senzala de Gilberto Freyre, publicada em 1933 no Brasil, por exemplo, não só traziam uma determinada interpretação do ethos nacional, como também traziam consigo uma concepção de nação. O exercício de imaginação da nação, nos termos postos por Anderson (2008), realizaram-se em grande medida a partir dos esforços das antropologias na América Latina.

Acredito que há aí uma primeira convergência importante entre a antropologia e a educação na América Latina, pois do mesmo modo que esta ciência emerge engajada nesse projeto de construção da nação, a educação passa a ocupar lugar semelhante nestas sociedades. A progressiva ampliação do acesso à educação escolar relaciona-se à construção de certos projetos de nação, que passa a assumir aspectos mais ou menos conservadores, a depender especialmente do contexto político no qual esses países estão inseridos em determinados momentos históricos.

Ainda que não nos interesse aqui aprofundar o debate sobre nação, o que escaparia do foco e do escopo desse artigo, é interessante ponderar a forte relação entre nação-antropologia-educação. E como veremos mais adiante, isso também se desdobra na presença da antropologia nos cursos de formação de professores em diversos países.

Partindo do caso argentino Blázquez (2012) analisa as atividades realizadas durante o centenário da independência da Argentina, cuja celebração implicou o desenvolvimento de várias "técnicas de 
nacionalização" que se relacionavam diretamente com o ambiente escolar, principalmente por meio da nacionalização do currículo e da promoção das performances patrióticas. Neste contexto a chamada "Educação Patriótica”, que visava “[...] superar la limitación de la enseñanza de los valores nacionales que estaba vinculada sólo a ciertas asignaturas que funcionaban como locus de la Nación en la escuela” (Blázquez, 2012, p. 131). Por meio desse novo espaço na escola, a performação da nação iria além de festejos pontuais, que se concentravam nos meses de maio e junho

Porém, há que se destacar também pontos de desencontros, pois, se para a antropologia interessou dar relevo à diversidade cultural, recorrentemente ao sistema escolar houve maior destaque para a tentativa de apresentar uma unidade cultural nacionalmente situada. A cultura é, portanto, recursivamente utilizada visando determinadas finalidades políticas que são ramificadas e performadas a partir da escola.

Sendo a cultura uma chave central para a educação escolar, não é de se espantar que a antropologia tenha passado a ganhar espaço nos cursos de formação de professores, o que significou também uma modernização nessas formações que passavam a contar cada vez mais com "ciências modernas" tais como a Sociologia e a Psicologia, além da antropologia. Porém a forma como esta ciência foi introduzida em tais cursos varia em cada contexto nacional. No Brasil, por exemplo, houve a criação de cátedras de Antropologia Pedagógica ainda nas primeiras décadas do século XX, porém assentadas largamente em uma Antropologia Biológica, sendo notória a influência de Cesare Lombroso (Oliveira, 2013b). Talvez uma primeira aproximação com a Antropologia Cultura na formação de professores possa ter como marco o curso de Sociologia que Gilberto Freyre realizou ainda no final da década de 1920 junto à Escola Normal de Pernambuco, que segundo o próprio autor era um curso de Sociologia com bases antropológicas, incluindo entre os tópicos explorados a sociologia da criança e da educação. No caso colombiano, Pachón $(2015)$ aponta para a primeira experiência do ensino de antropologia em cursos com esse caráter no ano de 1936, ofertado pela Faculdade Nacional de Educação.

Os dados trazidos aqui são importantes para reforçar a argumentação central desse artigo, de que a antropologia da educação ocupa um lugar periférico na agenda mais ampla da antropologia latino-americana. Se como bem observa Robins (2003), a antropologia da educação se faz presente incisivamente nos cursos de formação de professores, o mesmo não se pode dizer com relação a sua presença nos cursos de formação de antropólogos. Deste modo, podemos perceber que a antropologia da educação, ao menos institucionalmente, alocou-se principalmente nos espaços de formação docente, e só subsidiariamente nos departamentos de antropologia.

Todavia, é importante destacar que a institucionalização de uma antropologia da educação só foi possível ante ao próprio processo de institucionalização da antropologia nesses países, o que passou a se consolidar em diferentes ritmos a partir da segunda metade do século XX. Nesse contexto destacaria duas experiências singulares, que deixaram marcas significativas no desenvolvimento deste debate: o Departamento de Investigaciones Educativas (DIE) do Centro de Investigación y de Estudios Avanzados (CINVESTAV) do Instituto Politécnico Nacional (IPN) do México, e o Programa de Antropologia e Educação da Universidade de Buenos Aires. Se o primeiro é criado ainda nos anos 1970, o segundo surgirá duas décadas depois, sofrendo também uma forte influência do primeiro.

Uma das marcas mais evidentes nessas pesquisas se dá a partir da larga utilização da chamada pesquisa participante, cuja influência do legado de Eliza Rockwell e Justa Ezpeleta (1989), pesquisadoras do DIE, se faz de forma evidente. Para estas antropólogas, a escola é um espaço privilegiado para se pensar a sociedade em seu processo histórico a partir do seu cotidiano, conceito elaborado tendo por base os trabalhos de Heller. Para Tosta (2013, pp. 99-100):

As principais ideias apresentadas pelas autoras são: olhar o movimento social a partir de baixo; dar visibilidade aos sujeitos constituintes da comunidade escolar não como papéis definidos a priori, mas como parte constituinte da história de cada escola; buscar no cotidiano, reconhecendo seu conteúdo histórico, a presença de elementos civis e estatais, superando a visão dicotômica sobre a escola; considerar a escola documentada e a não documentada. As contribuições de Rockwell e Ezpeleta 
expressam um novo tipo de conhecimento sobre a realidade da escola e um compromisso de que esse conhecimento promova a transformação social. A proposta do DIE teve significativo alcance no cenário antropológico da Argentina e no educacional do Brasil.

Ou seja, trata-se de uma dada produção intelectual forjada no contexto mexicano, mas que acaba tendo um impacto bastante amplo sobre o desenvolvimento da antropologia da educação na América Latina. Retomo aqui a ideia que as antropologias aqui desenvolvidas possuem como marca incisiva sua criticidade, e isso também está presente na reflexão antropológica acerca da educação Latino Americana.

Há de se ressaltar que tanto no caso do DIE quanto no Programa de antropologia e educação, encontramos casos bastante singulares de institucionalização das pesquisas antropológicas em educação. No Brasil houve uma tentativa similar nos anos de 1950, quanto o educador Anísio Teixeira (1900-1971) fundou o Centro Brasileiro de Pesquisas Educacionais (CBPE), que visava, justamente realizar pesquisas sociológicas e antropológicas aplicadas no campo da educação. Sem embargo, essa proposta acabou não sendo exitosa, em parte porque muitos dos pesquisadores vinculados ao centro optaram por dedicar suas atividades a outros campos investigativos, e não necessariamente à educação (Dias Silva, 2002).

Assim, compreendo que a institucionalização de uma possível antropologia da educação em América Latina ocorre de modo relativamente frágil. Porém há de se considerar nesse cenário a própria heterogeneidade existente nas Ciências da Educação, marcada por uma multiplicidade de abordagens teóricas, metodológicas e epistemológicas. Sendo assim, ainda que por vezes se fizesse ausente um debate mais incisivo nos Programas de Pós-Graduação em antropologia sobre a educação, continuamente encontramos trabalhos que se propõe realizar uma aproximação antropológica com a educação a partir de cursos de mestrado e doutorado em Educação/Ciências da Educação.

Retoma-se ainda mais uma vez a ideia de que parte significativa da antropologia da educação, diferentemente do que ocorreu com outras áreas da antropologia, se desenvolveu institucionalmente "fora da antropologia”. Quero dizer com isso que os Departamentos/Faculdades de Educação terão um papel decisivo na institucionalização da antropologia da educação na América Latina, sendo um dos principais espaços de consagração intelectual para esse campo.

Voltando mais uma vez ao caso brasileiro, podemos observar uma presença bastante expressiva de antropólogos que se vinculam institucionalmente a Programas de Pós-Graduação em Educação, passando a se inserir academicamente a partir de tais espaços (Oliveira, 2017). Notadamente, deve-se também assumir que nas estruturas universitárias as Faculdades de Educação tendem a ser maiores, e mais centrais na correlação de forças, que os Departamentos de Antropologia, de modo que lá historicamente se agregam sociólogos, historiadores, filósofos, psicólogos e antropólogos dedicados à pesquisa educacional.

Isso implica em reconhecer também que o lugar que a antropologia da educação ocupa na agenda mais ampla da antropologia latino-americana, especial o lugar no qual acabou se institucionalizando, reflete as tensões, disputas e construções históricas que foram sendo construídas em torno das pesquisas educacionais. De forma relativamente semelhante podemos dizer que o mesmo ocorreu com a história da educação, filosofia da educação etc., que encontraram maior espaço para sua institucionalização junto às Faculdades de Educação, assumindo uma posição periférica na agenda dos Departamentos de história, filosofia etc.

Por fim, há de se considerar que, o parco interesse de muitos antropólogos sobre este tema pode ser explicado, em grande parte, pela exclusão nos sistemas escolares de populações que historicamente são objeto de reflexão sistemática da antropologia, tais como: negros, indígenas, mulheres e camponeses. O progressivo ingresso dessas populações nos sistemas escolares tem implicado também num crescente interesse por parte desses pesquisadores na escola, e não só, incluiria aí também o crescente interesse pela investigação envolvendo o universo universitário.

Esta questão terá uma implicação decisiva sobre a agenda de pesquisa da antropologia da educação na América Latina: a centralidade da questão da educação indígena nesse campo. Trata-se de abordagens que visam não apenas captar os processos de aprendizagem vivenciados de forma ampla pelas comunidades 
indígenas, como também questões que tangenciam as políticas de acesso à educação diferenciada por parte dessas comunidades.

Ademais, as próprias mudanças políticas e sociais que vêm ocorrendo em América Latina, com a elaboração de novas pautas políticas e reivindicatórias por parte de grupos indígenas, negros, campesinos etc., tem chamado ainda mais a atenção para as lógicas próprias de ensino e aprendizagem existentes nessas realidades. Percebo assim um crescente interesse dos Antropólogos Latino Americanos pela escola, mas também pelos processos de aprendizagens não escolares, e talvez seja aí onde haja uma interface bastante frutífera com a chamada antropologia da Infância, que nos possibilita destacar as múltiplas formas de aprendizagens possíveis (Cohn, 2006).

\section{Um diálogo desde o Sul}

O que irei trazer nessa segunda sessão não chega a ser algo exatamente novo, tendo em vista que a ideia de se pensar teorias do Sul, ou mais especificamente antropologias do Sul tem se constituído como uma questão para inúmeros pesquisadores não apenas na América Latina, como também em África, Ásia, Oceania, ou mesmo em países europeus que não integram essa antropologia Hegemônica Euro-Americana. Porém, tratase de pensar esta questão por um ângulo ainda pouco explorado, que é o da antropologia da educação.

Para Oliveira (2006), haveria claramente o que denominou de antropologias Periféricas, compreendidas nesses termos não dentro de uma hierarquia qualitativa com que relação ao que é produzido, mas sim dentro de uma hierarquia das relações de poder estabelecidas que criam distintas condições objetivas e subjetivas de produção do conhecimento. Mas o reconhecimento de tal questão não implicava, na perspetiva do autor, num abandono das pretensões universalistas da disciplina, que continuaria a articular os diversos paradigmas teóricos existentes, as mudanças seriam assim sobretudo mudanças de estilo, sem que com isso houvesse o abandono de uma "gramática comum". Tais mudanças estariam condicionadas por condições objetivas e subjetivas específicas, tais como: a concentração de investigações no território nacional, a debilidade institucional em termos de pesquisa, a dependência do exterior para a formação avançada de quadros, o mercado de trabalho aquém da demanda, ausência de periódicos de circulação internacional.

Certamente que o cenário atual não é o mesmo que Oliveira analisou, e muitos dos pontos levantados tem contado com um significativo desenvolvimento em boa parte dos países localizados nas diversas periferias, incluindo a América Latina. Por outro lado, penso que alguns outros pontos ainda são nefrálgicos, como a questão dos periódicos internacionais, que esbarra juntamente em uma questão político cultural: a língua, pois como nos indica Lins Ribeiro (2014), por mais contraditório que possa parecer, a possibilidade de criar múltiplos diálogos entre as diversas antropologias mundiais perpassa, obrigatoriamente, a necessidade dos pesquisadores colocarem seus conhecimentos em circulação a partir de um idioma comum, e o inglês em grande medida teria se tornado a língua franca em vários campos científicos, incluindo a antropologia.

Cadena (2012, p. 284) destaca que em inúmeras revisões realizadas acerca da Antropologia Andina, e da peruana em particular, a produção de autores peruanos é sistematicamente secundarizada em prol de produções realizadas em inglês por pesquisadores situados em países centrais. Sobre isso a autora coloca que:

Nós precisamos, pelo menos, romper o silêncio no qual ela prolifera. Universais na aparência, as formas de conhecimentos ocidentais e suas práticas não são confinadas à Europa ou aos Estados Unidos —elas têm ultrapassado aqueles territórios por mais de cinco séculos. Articuladas por uma vocação de difusão da razão, a moderna geopolítica do conhecimento estabeleceu um centro (Atlântico Norte) e foi além dele. Constituiu, assim, formaçôes acadêmicas (e intelectuais) regionais com seus próprios centros, onde as instituições da razão cresceram, e periferias, onde a lógica racional tinha uma presença estabelecida mais fraca. Essas formações regionais compreendem uma complexa configuração de múltiplos centros hierarquicamente organizados, alguns dos quais são "periféricos" em relação a outros "mais centrais".

Atravessa essa configuração, relações de dominação e subordinação estratificadas e pluridirecionadas contribuem para formatar o que eventualmente é considerado conhecimento universal e o que permanece como informação local — tanto mundialmente como em países específicos. De fato, esse "universal" e esse "local" são também relativos internamente a essa 
configuração. Até onde o conhecimento local alcança depende — nós acreditamos hegemonicamente — de sua "força teórica", o que é problemático se por isso nos referimos a uma prática de conhecimento que extrai noções gerais dos significados locais e, no processo, nega a singularidade deles.

Tais hierarquias se colocam de forma objetiva e subjetiva enquanto desafios para a elaboração de um diálogo entre as diversas antropologias periféricas. Ainda que se deva reconhecer que isso ocorre ante a um cenário profundamente complexo, envolvendo o que Lins Ribeiro (2005) denominou de "provincianismo da metrópole" e "metropolitismo da província”. Afinal, as antropologias desenvolvidas nas periferias tendem a conhecer relativamente bem as produções acadêmicas elaboradas na metrópole, além de suas próprias produções, ao passo que a metrópole tende a restringir seu conhecimento a suas próprias contribuições para o campo. A esta questão deve-se somar também aquelas postas por Chakrabarty (2000), que problematiza o próprio ponto de partida das teorias sociais forjadas no contexto europeu, que acaba por universalizar experiências particulares, isso se desdobra no caso da antropologia no que Grimson et al. (2011) denominam de "etnocentrismo teórico".

Talvez o desafio que se coloca de forma mais evidente para nós nesse momento seja justamente visibilizar a produção realizada na periferia, mas não apenas para que sejamos lidos e citados por autores de países centrais, incorporando uma lógica própria de produção do conhecimento ali existente (Connell, 2012), mas também para que possamos elaborar múltiplas inteligibilidades entre essas antropologias periféricas, através de um diálogo Sul-Sul.

É nesse sentido que as ideias elaboradas por Krotz (2007, p. 48) se fazem pertinentes, ao pensar uma antropologia do Sul, que não se equivale simplesmente a uma antropologia no Sul. Como bem nos esclarece o autor:

Es importante darse cuenta que la expresión "sureña" (y para la "norteña" vale lo propio) tiene dos significados relacionados pero distintos. Por una parte, "sureña" es sinónimo de en el Sur y se refiere simplemente a la antropología que se produce y practica en determinada región no perteneciente a la cuna noratlántica de la antropología originaria y sus descendientes directos. 10 Por otra parte, "sureña" puede tener también significar antropología del Sur, en el sentido de una práctica científica que asume explícitamente esta ubicación geo-políticocultural y se entiende como parte integrante de una tradición propia de la antropología universal que surgió principalmente por impulsos de difusión. En cualquiera de los dos significados, como ya se dijo, el término debe usarse en plural, ya que tanto en el Norte como en el Sur no existe un tipo único de antropología hegemónica, sino un conjunto de tradiciones nacionales y/o lingüísticas claramente diferenciadas.

Isso implica em dizer que pensar nossos diálogos é pensar nossa própria localização nessa geopolítica do conhecimento e as implicações daí decorrentes. Ademais, a elaboração de uma antropologia do Sul encontra seus próprios desafios, quais sejam:

El reducido aprecio del que goza la investigación cientifica y tecnológica en América Latina. Ésta se expresa, ejemplarmente, en el porcentaje minúsculo que esta actividad ocupa del Producto Interno Bruto y del presupuesto nacional en todos los países latinoamericanos y en el lugar real -quiere decir: independientemente de los discursos de aniversario etc. - que ocupa en los esquemas organizativos de las universidades que siguen siendo básicamente escuelas profesionales; también es importante señalar que en las expectativas de la población en general,la ciencia propia no suele jugar un papel relevante como posible fuente para la solución de los grandes problemas del país y del tiempo actual. También hay que mencionar aquí que en no pocas instituciones académicas priva una cultura política de tipo marcada por el autoritarismo y la sumisión,que fomenta la repetición de ideas conocidas al tiempo que bloquea la crítica creativa y la innovación audaz.

La debilidad de las instancias gremiales de las antropologías latinoamericanas, donde solamente la Asociación Brasileira de Antropología18 y la Red Centroamericana de Antropología19 han logrado establecer formas de organización eficientes y sostenidas. Pero aún así, parecen existir muy pocas muestras de que la antropología como actividad colectiva pueda resistir la transformación de programas de estudio y la imposición de formas de organizar y evaluar la investigación construidas conforme a modelos de las 
ciencias naturales y estéticas burocráticas, muchas veces procedentes de fuera;igualmente reducida parece ser la posibilidad de contrarrestar realmente la dependencia epistémica de fuentes de financiamiento privadas.

El diminuto conocimiento mutuo de las antropologías latinoamericanas que las priva a todas de la posibilidad de la comparación sistemática y acumulativa y, por consiguiente, del enriquecimiento mutuo y de la búsqueda de caminos comunes hacia una antropología arraigada cada vez más en la arriba llamada "cultura del Sur" y la búsqueda de su transformación hacia una realidad más digna para todos. (Krotz, 2007, pp. 54-55)

Considerando esses elementos, indago-me sobre as possibilidades que temos de pensar uma antropologia da educação na América Latina desde o Sul. É certo que essa antropologia compartilha dos demais desafios existentes para as antropologias Latino-Americanas em geral, porém, creio que há particularidades que tendem a aprofundar tais desafios, pois, se há um diminuto conhecimento mútuo envolvendo as antropologias produzidas na América Latina, esse conhecimento ainda é mais diminuto no caso de temas que não ocupam a agenda central de pesquisa nas diversas antropologias nacionais.

Por vezes, os próprios pesquisadores que investigam no campo da antropologia da educação em seus países desconhecem o que vem sendo produzido por seus pares, talvez isso se explique em parte pela particularidade que temos na antropologia da educação em que há uma profunda diversidade institucional de tais pesquisadores, alguns alocados juntos aos departamentos de Ciências Sociais ou antropologia, outros juntos às Faculdades de Educação, atuando mais diretamente com a formação de professores para as escolas. Recorrentemente os espaços de consagração acadêmica são outros, que envolvem a participação em eventos especializados no campo da educação, bem como a publicação em revistas em educação, que muitas vezes são menos lidas por antropólogos.

Mesmo em iniciativas institucionais de promoção do diálogo entre a antropologia e a educação, como no caso da comissão de "Antropologia e Educação" da International Union of Anthropological and Ethnological Sciences (IUAES), cujos primeiros congressos datam de 1934, observa-se que majoritariamente a discussão centra-se no ensino de antropologia, e pouco numa reflexão antropológica do objeto educacional.

Pensando no caso brasileiro, fica evidente a partir das participações que ocorrem nas Reuniões Brasileiras de antropologia, que a maior parte daqueles que coordenam Grupos de Trabalho, participam de mesas redondas etc. são antropólogos que atuam em Faculdades de Educação, e que devido aos processos de avaliação institucional pelo qual passam os programas de pós-graduação, tendem a concentrar suas produções em periódicos de educação e não de antropologia, o que implica em certa invisibilização de seus trabalhos ante aos pares da antropologia.

Sendo assim, além da complexa geopolítica do conhecimento que secundariza a produção das antropologias "não hegemônicas", internamente, no próprio campo das antropologias nacionais o que é produzido pela antropologia da educação torna-se secundário e circula menos nas redes de colaboração e de trocas intelectuais, especialmente naquelas produzidas entre as antropologias periféricas. Neste ponto, este caso esbarra na seguinte questão:

Há uma ambiguidade que indaga: qual a pluralidade interna que deva ser valorizada, e qual a pluralidade interna que deva ser suprimida? Ao nível geopolítico da nação, especialmente quando se trata de nações de dimensões geográficas significativas, há uma repetiçaõ da supressão da história e da complexidade internas, já referida como parte da realidade discursiva centro-periferia que tanto incomodava a Eric Wolf (1982). Para que a pluralidade entre antropologias nacionais, a ser representada pelos antropólogos mais internacionalmente conectados, seja respeitada, opera-se uma hierarquia que engloba a multiplicidade de antropologias locais sob o manto da qualidade e internacionalização, com supervalorização da produção acadêmica e subvalorização da "inserção social" de antropologias que se envolvem na defesa de populações específicas. (Scott, 2014, pp. 146-147)

As antropologias latino-americanas, como já argumentado, são historicamente engajadas e comprometidas com as populações locais, no caso da antropologia da educação aqui desenvolvida isso fica ainda mais evidente, pois as discussões tangenciam amiúde às demandas de acesso ao sistema de ensino oficial, bem como à formulação de políticas educacionais próprias para determinadas populações específicas, havendo 
recorrentemente um engajamento explícito desses pesquisadores nas realidades sociais pesquisadas (Oliveira et al., 2016). Neste sentido, o que é produzido nesta seara estaria situado numa posição hierárquica inferior em termos dessa geopolítica acadêmica.

Acrescentaria ainda que dentro de nossas próprias tradições nacionais ainda nos conhecemos pouco, via de regra, o que poderia ser alterado mediante a criação de espaços próprios para a circulação do debate particular da antropologia da educação, refiro-me aqui sobretudo a periódicos de livre acesso e fóruns de discussão, envolvendo tanto antropólogos quanto as populações diretamente interessada nas questões educacionais debatidas por essa comunidade acadêmica. Este desafio deve ser encarado de forma concomitante também ao de nos conhecermos também para além das fronteiras nacionais, recapitulando de forma comparativa as diversas experiências de investigação da antropologia da educação na América Latina.

O que quero destacar com isso é que no caso da antropologia da educação na América Latina estamos diante de uma situação de uma dupla colonialidade, externa (com relação às antropologias hegemônicas) e interna (com relação às questões que centralizam as agendas de pesquisa das antropologias Latino Americanas). Sendo assim, o locus da educação na agenda de pesquisa da antropologia na América Latina obedece à lógica do colonialismo interno dessa disciplina. Neste sentindo, coaduna para o debate aqui estabelecido as questões trazidas por Restrepo (2007, p. 300):

En tanto disciplina, la antropología implica una serie de prácticas institucionalizadas y modalidades de producción y regulación de discursos (Escobar 1993: 379). En el ámbito académico, las prácticas institucionalizadas y las relaciones de poder configuran en diferentes y sutiles maneras la producción, circulación y consumo del conocimiento antropológico así como la producción de ciertas posiciones de sujeto y subjetividades (Trouillot 1991: 18). Estas 'microprácticas de la academia' definen no sólo una particular rejilla de enunciabilidad, autoridad y autorización, sino también las condiciones de existencia (y transformación) de la antropología como una disciplina académica particular. La mayoría de las microprácticas son tomadas por sentadas constituyendo una suerte de sentido común disciplinario y un punto ciego que rara vez es objeto de escrutinio sistemático. En este sentido, Eval Ben-Ari argumenta que “[...] aunque somos muy buenos analizando cómo la antropología crea varios otros tales como los 'nativos' o los 'locales', somos menos aptos para analizar rigurosamente cómo creamos y recreamos los 'antropólogos”' (1999: 390).

La colonialidad opera en este plano mediante mecanismos institucionales (como las políticas editoriales, la predominancia de unas lenguas y de los textos escritos, los formatos de argumentación, la sedimentación de genealogías y cánones disciplinarios, los procesos de formación universitarios, etc.) que implican la hegemonización de unas tradiciones y modalidades del establecimiento antropológico, al tiempo que subalternizan (silencian) otras (Krotz 1993, Ribeiro y Escobar 2006).

O diálogo Sul-Sul no campo da antropologia da educação, pensado desde a América Latina, perpassa, assim, o reconhecimento de hierarquias internas e externas do campo mais amplo da antropologia, e de como elas operam objetivamente e subjetivamente, uma vez que os pesquisadores tendem a se voltar para objetos de investigação de maior prestígio na vida acadêmica (Bourdieu, 2011). O fato é que, da forma como foi se constituindo a agenda de pesquisa da antropologia na América Latina a educação ficou relegada como um objeto menor, restrito às Faculdades de Educação, nas quais a presença da antropologia também sempre foi periférica, sendo mais presente as interfaces com a história, a sociologia e a psicologia no campo de formação de professores, ainda que se deva reconhecer aqui o valor inestimável da antropologia para tanto (Oliveira, 2014; Gusmão, 2016). Reconhecimento acompanhado de questionamentos, que nos incitem à construção de novas redes, estas pensadas não apenas entre antropólogos, mas abarcando tanto os sujeitos de pesquisa, as populações implicadas nos processos educativos pesquisados.

\section{Considerações finais}

Dentro dos limites desse trabalho busquei apresentar algumas questões que me parecem atuais para compreendermos o desenvolvimento institucional da antropologia da educação na América Latina. Não se tratou de uma retomada histórica do desenvolvimento institucional desse campo de pesquisa, reconhecido 
desde o princípio como bastante fragmentado e heterogêneo institucionalmente, apresentando graus distintos de desenvolvimento nos diversos países da região em questão, mas sim de uma análise que considera as estruturas de poder construídas e vislumbra quais as possibilidades postas.

Retomei o argumento já acionado por outros autores (Lins Ribeiro, 2005; Krotz, 2007; Restrepo, 2007; Grimson et al., 2011; Lins Ribeiro e Escobar, 2012; Scott, 2014) que problematiza as hierarquizações existentes no campo da antropologia, e de como a antropologia latino-americana especialmente se situa nesse processo, articulando com a questão educacional.

Minha hipótese principal é que a fragmentação institucional da antropologia da educação, justamente com o reconhecimento da educação como um objeto de parco prestígio na agenda de pesquisa dessa ciência faz com que haja aqui uma dupla colonialidade, interna e externa, que se desdobra numa condição duplamente periférica antropologia da educação produzida na América Latina. Periférica por ser produzida desde essa região geopolítica, e periférica por ser invisibilizada enquanto campo próprio de investigação antropológica, ainda que este seja um cenário dinâmico e em contínua transformação.

Por fim, proponho que uma forma que se pode buscar a superação dessa dupla condição reside, justamente, na tentativa de criação de espaços de diálogo Sul-Sul entre as antropologias da educação na América Latina, não restritos aos espaços institucionais acadêmicos, por compreender como fundamental que estes diálogos também englobem os sujeitos de pesquisa dessas realidades, tendo em vista as singularidades que envolvem a pesquisa em educação desde a antropologia.

\section{Referências}

Anderson, B. (2008). Comunidades imaginadas: reflexões sobre a origem e difusão do nacionalismo. Companhia das Letras.

Blázquez, G. (2012). Los actos escolares: el discurso nacionalizante en la vida escolar. Miño y Dávila.

Bourdieu, P. (2011). Homo academicus. EDUFSC.

Cadena, M. (2012). A produção de outros conhecimentos e suas tensões: da antropologia andina à interculturalidad? Em G. Lins Ribeiro e A. Escobar (eds.), Antropologias Mundiais: transformações da disciplina em sistemas de poder (pp. 283-314). Editora UnB.

Chakrabarty, D. (2000). Provincializing Europe: postcolonial thought and historical differenc. Princeton University Press.

Cohn, C. (2006). Antropologiada criança. Jorge Zahar Ed.

Connell, R. (2006). Southern theory: the global dynamics of knowledge in social science. Polity Press.

Connell, R. (2012). A iminente revolução na teoria social. Revista Brasileira de Ciências Sociais, 27(80), 9-20.

Dias Silva, G. (2002). Sociologia da sociologia da educação: caminhos e desafios de uma policy science no Brasil (1920-1979). Edusf.

Grimson, A., Merenson, S., e Noel, G. (2011). Descentramientos teóricos. Introducción. Em Antropología ahora. Debates sobre la alteridad (pp. 9-33). Siglo XXI Editores.

Gusmão, N. (2016). Antropologia, cultura e educação na formação de professores. Anthropológicas, 27(1), 45-71.

Jimeno, M. (2005). La vocación crítica de la antropología en Latinoamérica. Antipoda, (1), 43-66.

Krotz, E. (2007). Las antropologías latinoamericanas como segundas: situaciones y retos. En F. García (ed.), II Congreso Ecuatoriano de Antropología y Arqueología. Balance de la última década: Aportes, Retosy nuevos temas (pp. 41-59). Vol. I. Abya-Yala.

Lins Ribeiro, G. (2005). Antropologias mundiais: cosmopolíticas, poder e teoria em antropologia. Série Antropologia, 379, 1-16. 
Lins Ribeiro, G. (2014). Antropologia como cosmopolítica. Antropologia globalizante hoje. Em P. Scott, R. B. C. Campos e F. Pereira (eds.), Rumos da antropologia no Brasil e no mundo: geopolíticas disciplinares (pp. 99-125). Ed. UFPE.

Lins Ribeiro, G., e Escobar, A. (2012). Transformações disciplinares em sistemas de poder, G. Lins Ribeiro e A. Escobar (orgs.), Antropologias Mundiais: transformaçôes da disciplina em sistemas de poder (pp. 15-50). Editora Unb.

Medina, A. (1993). La etnografía como reflexión en torno a la nación: tres experiencias. Alteridades, 3(6), 67-72.

Oliveira, A. (2013a). Antropologia e/da Educação no Brasil: entrevista com Neusa Gusmão. Cadernos de Campo, 22(22): 147-160.

Oliveira, A. (2013b). O lugar da antropologia na formação docente: um olhar a partir das escolas normais. Pro-Posições, 24(2), 27-40.

Oliveira, A. (2014). A antropologia e a formação de professores. Revista Cocar, 8(14), 23-30.

Oliveira, A. (2017). Uma antropologia fora do lugar? Um olhar sobre os antropólogos na educação. Horizontes Antropológicos, 23(49), 233-253.

Oliveira, A., Búrigo, B. D., e Boin, F. (2016). A antropologia, os antropólogos e a educação no Brasil. Antropológicas, 27(1), 21-44.

Oliveira, R. C. (2006). O trabalho do antropólogo. Editora UNESP.

Pachón, X. (2015). La infancia y la antropología colombiana. Una aproximación. Em M. Díaz e M. Caviedes (eds.), Infancia y educación: analiss antropológico (pp. 135-154). Editorial Pontificia Universidad Javeriana.

Quijano, A. (2010). Colonialidade de poder e classificação social. Em B. S. Santos e M. P. Meneses (eds.), Epistemologias do Sul (pp. 84-130). Cortez.

Restrepo, E. (2007). Antropología y colonialidad. Em S. Castro-Gómez e R. Grosfoguel (eds.), El giro decolonial. Reflexiones para una diversidad epistémica más allá del capitalismo global (pp. 289-304). Pontificia Universidad Javeriana/Instituto Pensar/Universidad Central/Iesco/Siglo del Hombre Editores.

Robins, W. J. (2003). Un paseo por la antropología educativa. Nueva Antropología, 19(62), 11-23.

Rockwell, E., e Ezpeleta, J. (1989). Pesquisa participante. Cortez.

Scott, P. (2014). Poder, pluralidade estratégica e hierarquização interna em antropologias nacionais. Em P. Scott, R. B. C. Campos e F. Pereira (eds.), Rumos da antropologia no Brasile no mundo: geopoliticas disciplinares (pp. 127-158). Ed. UFPE.

Stocking Jr., G. W. (1982). Afeter world: a view from the center. Ethnos, 47(1-2), 172-186.

Tosta, S. (2013). Cruzando fronteiras - entre a antropologia e a educação no Brasil e na Argentina. Pro-Posições, 24(2), 95-107.

Licencia Creative Commons CC BY 4.0

* Artigo de pesquisa

Cómo citar este artículo: Oliveira, A. (2020). A periferia na periferia: sobre o lugar da antropologia da educação na antropologia latino-americana. Universitas Humanistica, 89. https://doi.org/10.11144/Javeriana.uh89. ppla 